\author{
B. K. Kizilduman ${ }^{1}$, M. Alkan², M. Doğan ${ }^{1 *}$ Y. Turhan ${ }^{1}$ \\ ${ }^{1}$ Balikesir University Faculty of Science and Literature Department of Chemistry 10145, \\ Cagis-Balikesir, Turkey \\ ${ }^{2}$ Paşaalanı Mahallesi Karesi-Balıkesir, Turkey \\ *mdogan@balikesir.edu.tr
}

\title{
AI-PILLARED-MONTMORILLONITE (AIPMt)/POLY(METHYL METHACRYLATE)(PMMA) NANOCOMPOSITES: THE EFFECTS OF SOLVENT TYPES AND SYNTHESIS METHODS
}

\begin{abstract}
Al-pillared-montmorillonite (AlPMt)/poly(methyl methacrylate)(PMMA) nanocomposites were synthesized via melt blending method (MBM) and solution blending method (SBM). FTIR-ATR spectroscopy proved the interaction of AlPMt with PMMA polymer matrix. The thermogravimetric and differential scanning calorimeter analyses showed that the thermal stability and the glass transition temperature $\left(T_{\mathrm{g}}\right)$ of polymer matrix shifted to higher temperatures with increasing AlPMt content. Images showed that AlPMt dispersed at nanometer scale in polymer matrix. Contact angle measurements demonstrated that the hydrophilicity of the PMMA increased with incorporation of AlPMt. However, the thermal stability of clay/polymer nanocomposites (CPNs) was significantly changed with CPN preparation method.
\end{abstract}

Keywords: Poly(methyl methacrylate), Al-pillared-montmorillonite, nanocomposite, thermal stability

\section{INTRODUCTION}

Polymers are widely used in various technical applications because of their unique advantages such as ease of production, light weight and ductility. However, they have lower mechanical, thermal stability, modulus and strength properties compared to that of metals and ceramics. The commercial importance of polymers and their increasing uses result to the continuous demand for improvement in their properties to meet the necessary conditions [1]. Poly(methyl methacrylate) (PMMA) is a typical transparent amorphous polymer, which is used in various field such as computers, fiber optics, 3D illuminated panels, solar deflectors, orthodontic equipment of our daily life. However, its poor thermal stability has limited its application in these areas. To improve the heat resistance, preparation of nanocomposite is an effective way [2-4].

The most heavily used filler material is based on the smectite class of aluminum silicate clays, of which the most common representative is montmorillonite (Mt). The Mt minerals occur as very small micron sized particles and they are extremely fine-grained and thinlayered. The layer of Mt has a thickness about $1 \mathrm{~nm}$ and a length of $100 \mathrm{~nm}$ or a little more [5]. Mt has been employed in many layered clay/polymer nanocomposite (CPN) systems because it has a potentially high-aspect ratio and high-specific surface area that could lead to 
materials which could possibly exhibit great property enhancements. In addition, it is environmentally friendly, naturally occurring, and readily available in large quantities [6].

Nanocomposites can be prepared by dispersing of silicate layers in a polymeric matrix, using three main methods: in situ polymerization, solution blending and melt blending methods [7]. Each method using to disperse of nanoparticles into the polymer matrix has some disadvantages and limitations. The most important disadvantage for SBM is absence of the appropriate solvent. Because intercalation/dispersion occurs only a specific polymer-solvent pairs [6]. Therefore, in this method, the solvent plays an important role in determining the properties of CPNs. Dispersion of clay particles for each polymer is a topic that has to be investigated [8]. Layered clay/polymer composites can be classified in three different types: conventional micro composites where stacks of silicate layers are dispersed at a microscale inside the matrix, intercalated nanocomposites in which some polymeric chains are able to insert between the platelets maintaining a long range order, and exfoliated nanocomposites in which the platelets are not ordered anymore but separately and homogeneously dispersed into the matrix as single platelets. In many cases, a mixture of intercalated and exfoliated structures is obtained, thus single platelets and particles are both present in the material. The best final properties are achieved when the clay mineral platelets are fully exfoliated and well dispersed [9-12]. In order to have a successful development of CPNs, it is necessary to modify natural clay so that it can be compatible with a chosen polymer matrix. Moreover, a suitable modification can enhance the interlayer space of the clay mineral and, thus, facilitate a better swelling of the clay mineral itself in an organic polymer or monomer [12].

Various methods such as intercalation, acid-activation and pillaring can be used in the modification of clays to improve the characteristics and qualities. Intercalation is insertion of a guest species in the interlayer space of a layered solid with preservation of the layered structure $[13,14]$. Treatments of clay minerals with organic acids at rather high concentrations and usually at high temperatures are known as acid activation. Acid treatments of clay minerals are an important control over mineral weathering and genesis. This process generally increases the specific surface area and acidity of clay minerals [15]. Pillaring is a commonly used procedure to transform a layered crystalline inorganic compound into a thermally stable material with microporosity and mesoporosity. Pillared clays can be prepared from both starting clay materials and pillaring agents [16]. Pillared clays based on metal oxide are of great importance because of their high thermal stability, high specific surface area and intrinsic catalytic activity. Pillared clays are usually prepared by ion-exchanging cations in the interlayer space of swelling clays [15].

There are many reports describing the preparation of PMMA nanocomposites by Mt. But none of these papers deal with importance of AlPMt in PMMA matrix. Gong et al. highlighted the effects of organophilic Mt in polyvinyl chloride (PVC) matrix and they synthesized nanocomposites by in situ intercalative polymerization. $\mathrm{T}_{\mathrm{g}}$ temperatures of synthesized nanocomposites were higher than neat polymer. Also, the nanocomposites enhanced the formation of residue and improved the thermal stability of the polymer matrix [17]. Modak et al. synthesized Mt/PMMA nanocomposites using imidazolium-based ionic liquids by a onepot method. The fact that synthesized samples increased the thermal stability, mechanical properties and $\mathrm{T}_{\mathrm{g}}$ temperature according to neat PMMA indicated the formation of nanocomposites [18]. Huskic et al. investigated the influence of a quaternary ammonium salt and $\mathrm{Mt}$ on the in situ intercalative polymerization of PMMA [19]. As a result, they improved its thermal stability, particularly at temperatures up to $280^{\circ} \mathrm{C}$, and Huskic and Zigon prepared Mt/PMMA nanocomposites by one-step in situ intercalative solution polymerization. Modify montmorillonite did not influence $\mathrm{T}_{\mathrm{g}}$ temperatures of nanocomposites. The thermal stability of PMMA increased and depended on filler material concentration [20]. In this study, unlike 
organophilic Mt, the preparation and characterization of PMMA nanocomposites filled with $1.0,2.5,5.0 \mathrm{wt} \%$ of AlPMt using MBM and SBM is reported to determine $i$. the best suitable method and solvent for AlPMt/PMMA nanocomposites, and ii. the effect of the amount of nanofiller on the morphology and thermal properties of AlPMt/PMMA nanocomposites. The structural and morphological characteristics of CPNs were verified by XRD, AFM and TEM analyses; their $T_{\mathrm{g}}$ temperatures were measured by differential scanning calorimeter (DSC) and the thermal stability by thermogravimetric analysis (DTA/TG). Contact angle measurements were made with Attension Theta Lite. Additionally, dispersions of AlPMt/PMMA nanocomposites in organic solvents were also investigated.

\section{MATERIAL AND METHODS}

AlPMt was supplied from Sigma-Aldrich and its specific surface area was $250 \mathrm{~m}^{2} / \mathrm{g}$. PMMA, which had a molecular weight of $35.000 \mathrm{~g} / \mathrm{mol}$, was bought from Across Organics. Solvents used in CPN synthesis such as $\mathrm{C}_{6} \mathrm{H}_{5} \mathrm{CH}_{3}$ (toluene) (T), $\mathrm{C}_{3} \mathrm{H}_{6} \mathrm{O}$ (acetone) (A), $\mathrm{C}_{4} \mathrm{H}_{8} \mathrm{O}$ (tetrahydrofuran) (THF) were purchased from Sigma-Aldrich and $\mathrm{CHCl}_{3}$ (chloroform) (Ch) purchased from Merck. In this study, all other chemicals were analytical grade and used without further purification.

\section{CPN Synthesis - MBM}

A co-rotating twin-screw-microcompounder DSM xplore was used for compounding AlPMt/PMMA nanocomposites. Before melt processing, PMMA and AlPMt were dried at 50 ${ }^{\circ} \mathrm{C}$ under vacuum oven for 24h. PMMA and AlPMt were dry-mixed by shaking in a plastic case for $5 \mathrm{~min}$ before feeding into the compounder. AlPMt contents of CPNs were 1.0, 2.5 and $5.0 \mathrm{wt} \%$. PMMA and AlPMt were added to a co-rotating twin-screw-microcompounder by using feeding units, respectively. AlPMt/PMMA nanocomposites were prepared in a twinscrew extrude machine at a screw speed of $80 \mathrm{rpm}$, melt temperature at $200^{\circ} \mathrm{C}$ for each sample. After mixing, CPN films were dried in a vacuum oven at $50^{\circ} \mathrm{C}$ for $48 \mathrm{~h}$ prior to characterization.

\section{CPN Synthesis - SBM}

Different amounts of AlPMt and $50 \mathrm{~mL} \mathrm{A,} \mathrm{T,} \mathrm{THF} \mathrm{and} \mathrm{Ch} \mathrm{were} \mathrm{added} \mathrm{to} \mathrm{different}$ reaction vessels, respectively. These dispersions were treated in ultrasound bath for $20 \mathrm{~min}$. Then, AlPMt dispersions were stirred with magnetic stirring for $2 \mathrm{~h}$. After stirring for $2 \mathrm{~h}$, these dispersions were re-treated in ultrasound bath for $20 \mathrm{~min} .1 \mathrm{~g}$ PMMA in $50 \mathrm{~mL} \mathrm{A,} \mathrm{T,}$ THF and Ch was added to different reaction vessels and dissolved at room temperature (RT). When PMMA was completely dissolved, AlPMt dispersions were added into PMMA solution flask and mixed together at RT for $24 \mathrm{~h}$. The samples were poured into glass Petri dishes and the solvents were evaporated at $40^{\circ} \mathrm{C}$ in a vacuum oven for 7 days. Finally, AlPMt/PMMA nanocomposites were obtained [21].

\section{X-Ray Diffraction Patterns}

X-ray diffraction patterns (XRD) were obtained using Analytical Philips X'Pert-Pro Xray diffractometer equipped with a back monochromator operating at $40 \mathrm{kV}$ and a $\mathrm{Cu}$ cathode as the X-ray source $(\lambda=1.54 \AA)$ at RT. The diffraction curves were obtained from $5-50^{\circ}$ at a scan rate of $2 \% \mathrm{~min}$. 


\section{Transmission Electron Microscopy (TEM)}

TEM micrographs of CPNs were obtained with a FEI Tecnai G2 F30 using an acceleration voltage of $200 \mathrm{kV}$.

\section{Atomic Force Microscopy (AFM)}

The morphology analysis of AlPMt/PMMA nanocomposites was investigated with Nanosurfeasy Scan 2 STM AFM. AFM measurements were carried out constant amplitude of $40 \mathrm{mV}$ by using "tapping mode" probe in the RT and air conditions. Specific surface areas were analyzed with $190 \mathrm{kHz}$ frequency.

\section{Infrared Spectroscopy}

Infrared spectra of samples were obtained using a Perkin Elmer Spectrum 100 FTIR-ATR for scanning coverage from 650 to $4000 \mathrm{~cm}^{-1}$ in the transmission mode.

\section{Thermogravimetry}

The thermal stability of CPNs was performed using a Perkin Elmer Diamond DTA/TG. The average amount of samples was 3-10 mg in the TG measurements. Samples were heated from RT to $600^{\circ} \mathrm{C}$ at a heating rate of $10^{\circ} \mathrm{C} / \mathrm{min}$ under $\mathrm{N}_{2}$ atmosphere. The analysis was carried twice for each sample.

\section{$T_{g}$ Temperature Analysis}

$\mathrm{T}_{\mathrm{g}}$ temperatures of $\mathrm{CPNs}$ were measured by differential scanning calorimeter (Perkin Elmer DSC 4000 calorimeter) at a heating or cooling rate of $20{ }^{\circ} \mathrm{C} / \mathrm{min}$ under $\mathrm{N}_{2}$ atmosphere between RT and $250^{\circ} \mathrm{C}$.

\section{Contact Angle Measurements}

Contact angle measurements of CPNs were carried out with Attension Theta Lite at RT by preparing aqueous solutions. The volume of the sessile drop was hold steady approximately $10 \mu \mathrm{L}$ in all cases using a microsyringe. The contact angle was measured within 45-60 s of the addition of the liquid drop with an accuracy of $\pm 1^{\circ}$. Additionally, contact angles were measured with certain time intervals for a single drop and measurements were recorded as snap shots.

\section{RESULT AND DISCUSSION}

\section{XRD and FTIR-ATR Analysis of AlPMt}

Figure 1 shows the XRD pattern and FTIR-ATR spectrum of AlPMt. The characteristic reflections of AlPMt around $2 \theta=5.54^{\circ}, 2 \theta=19.76^{\circ}$ and $2 \theta=21.85^{\circ}$ have been observed from XRD pattern. Distances between the layers which was calculated by the Bragg law are $\mathrm{d}=15.95 \AA, \mathrm{d}=4.49 \AA$ and $\mathrm{d}=4.07 \AA$, respectively. In FTIR-ATR spectrum, AlPMt showed stretching of hydroxyls bonded to the aluminum and magnesium $[\mathrm{Al}(\mathrm{Mg}) \mathrm{OH}$ or $\mathrm{Al}(\mathrm{Al}) \mathrm{OH}]$ and decreasing in intensity of the band being the characteristic peak of water adsorption in clays $\left(3634 \mathrm{~cm}^{-1}\right)[5,12,22]$, the great/wide signal from trapped water molecules $\left(3455 \mathrm{~cm}^{-1}\right)$, OH-bending vibration of coordinated $\mathrm{H}_{2} \mathrm{O}\left(1634 \mathrm{~cm}^{-1}\right)$, a low intensity peak which has been appointed to the $\mathrm{O}-\mathrm{H}$ bending mode of the $\mathrm{Fe}(\mathrm{III}) \mathrm{AlOH}\left(920 \mathrm{~cm}^{-1}\right)$ [23]. 
a)

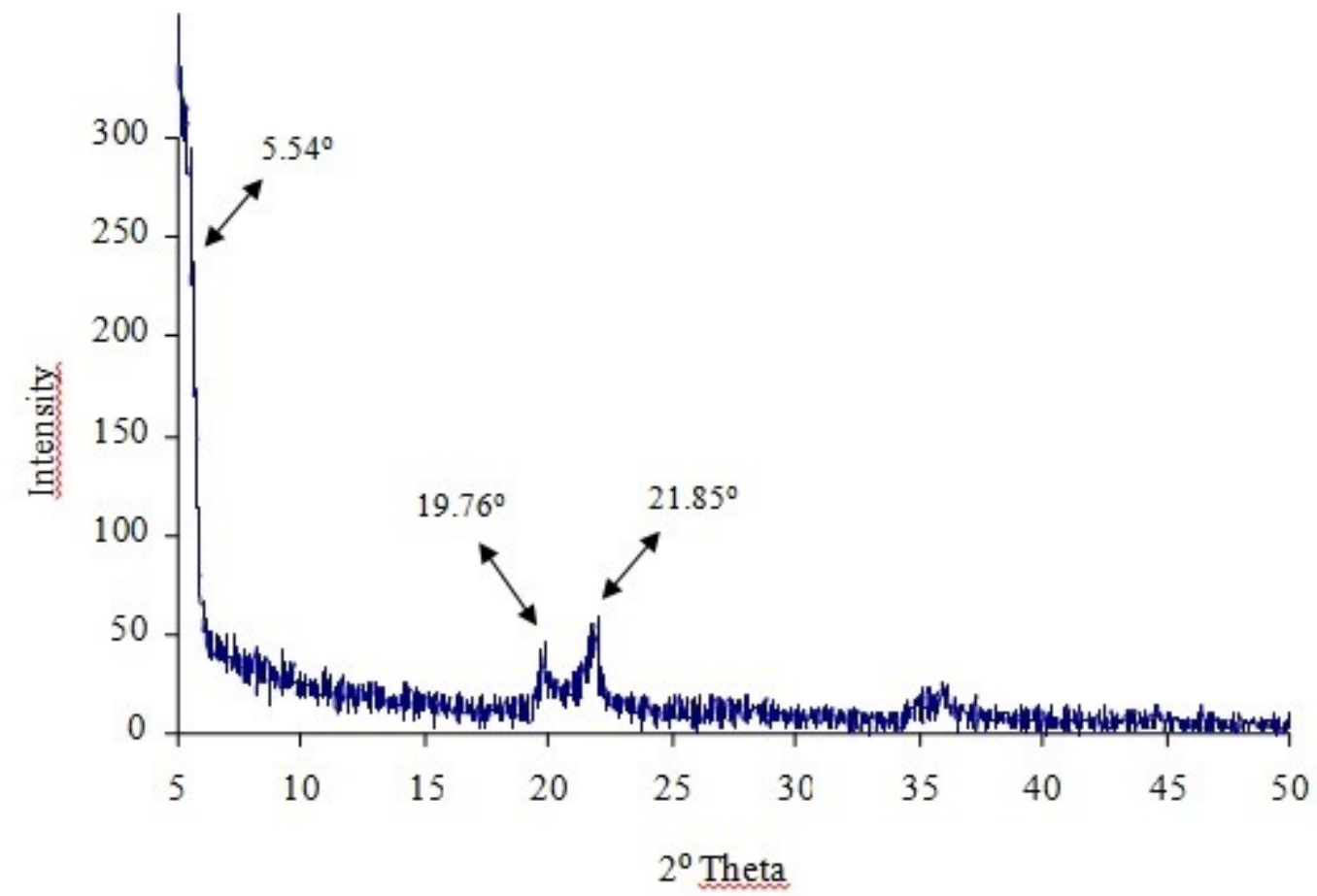

b)

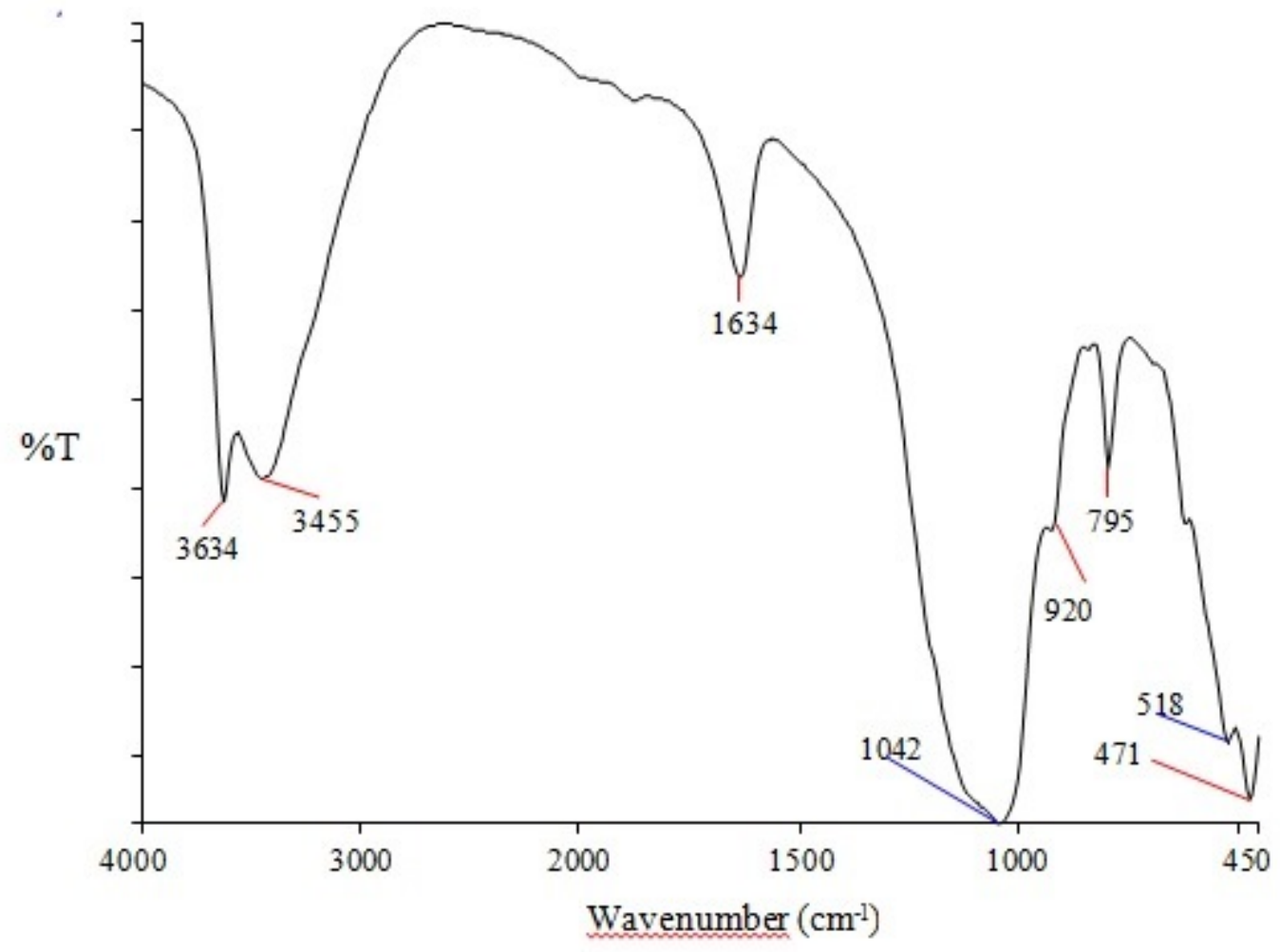

Fig. 1. a) XRD pattern, b) FTIR spectrum of AIPMt

XRD Analysis of Nanocomposites

Degree and determination of silicate dispersion are possible with XRD measurements. In general, systems are followed with change of polymer/silicate layers in space of $2 \theta=3-9^{\circ}$ [24]. In the characterization of CPNs, interaction between polymers and fillers can be determined 
from reflections belonging to distance between 001 planes of clays in the XRD patterns. Figure 2 shows XRD patterns of different filler compositions of AlPMt/PMMA nanocomposites that were prepared with MBM. From Fig. 2, nanocomposite XRD patterns show an increasingly amorphous material and it has been understood that AlPMt has dispersed as homogeneous into PMMA matrix because the characteristic reflection of AlPMt was not found in XRD patterns. Despite increase of clay amount, any differences have not been observed on dispersion. Furthermore, different nanocomposite preparation methods did not change dispersion. Thus, in this study, selection of solvent were made according to the solubility parameter values of PMMA and solvents (Solubility parameters; $\delta_{\text {acetone }}: 9.77$ $\left(\mathrm{cal} / \mathrm{cm}^{3}\right)^{1 / 2}, \delta_{\mathrm{THF}}: 9.52\left(\mathrm{cal} / \mathrm{cm}^{3}\right)^{1 / 2}, \delta_{\text {chloroform}}: 9.21\left(\mathrm{cal} / \mathrm{cm}^{3}\right)^{1 / 2}, \delta_{\text {toluene }}: 8.91\left(\mathrm{cal} / \mathrm{cm}^{3}\right)^{1 / 2}$, $\left.\delta_{\text {PMMA }}: 9.25\left(\mathrm{cal} / \mathrm{cm}^{3}\right)^{1 / 2}\right)[25-28]$.

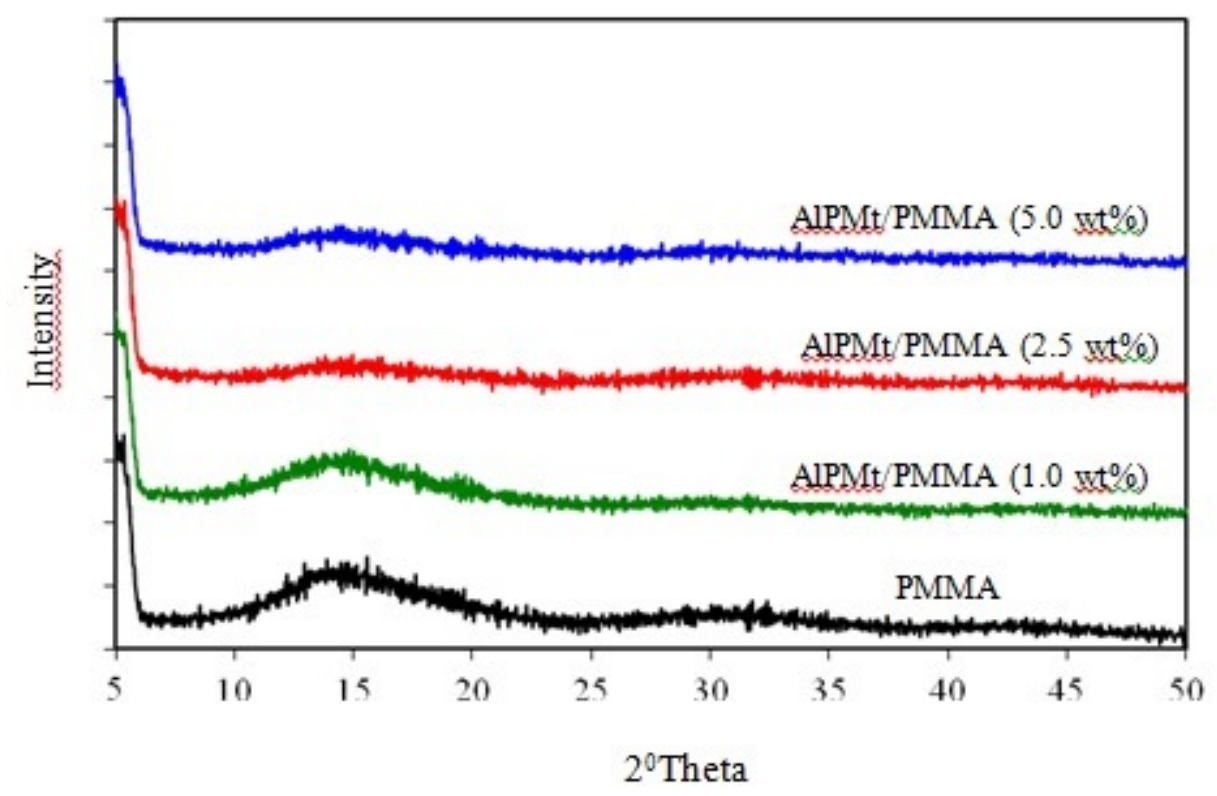

Fig. 2. XRD patterns of AIPMt/PMMA nanocomposites with MBM

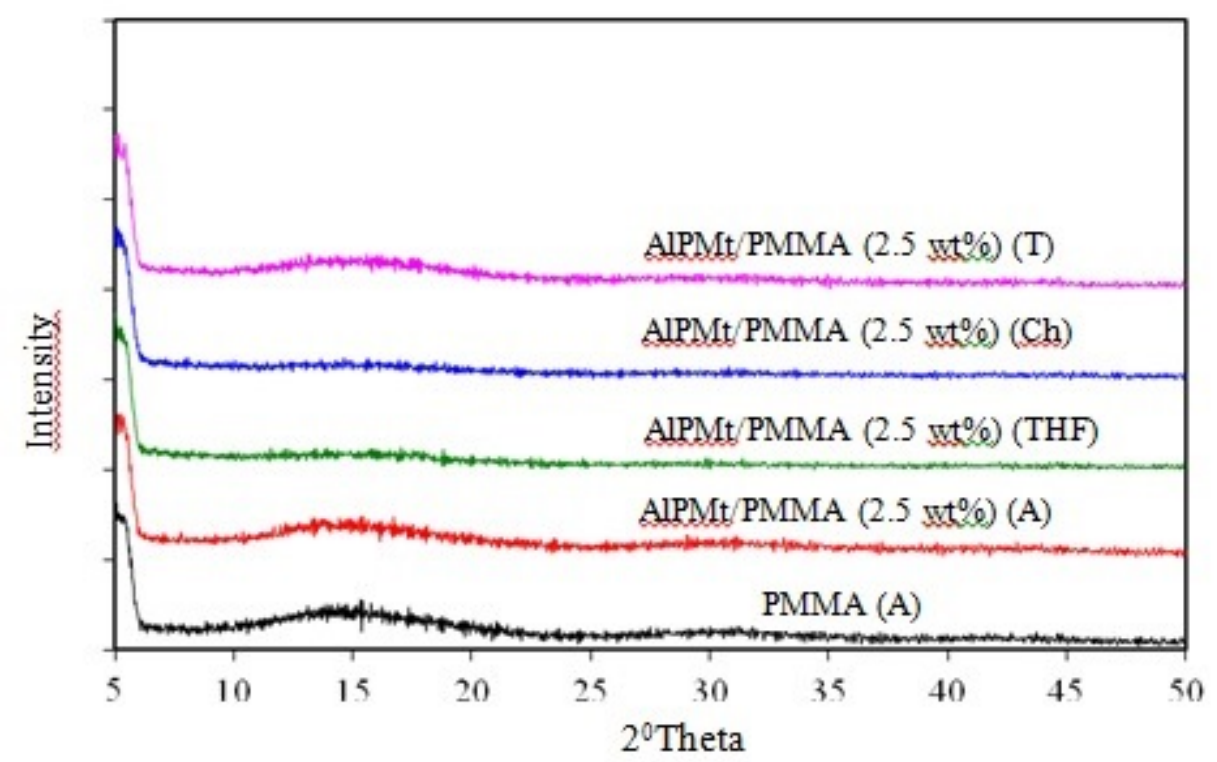

Fig. 3. XRD patterns of AIPMt/PMMA nanocomposites with SBM by using different solvents 


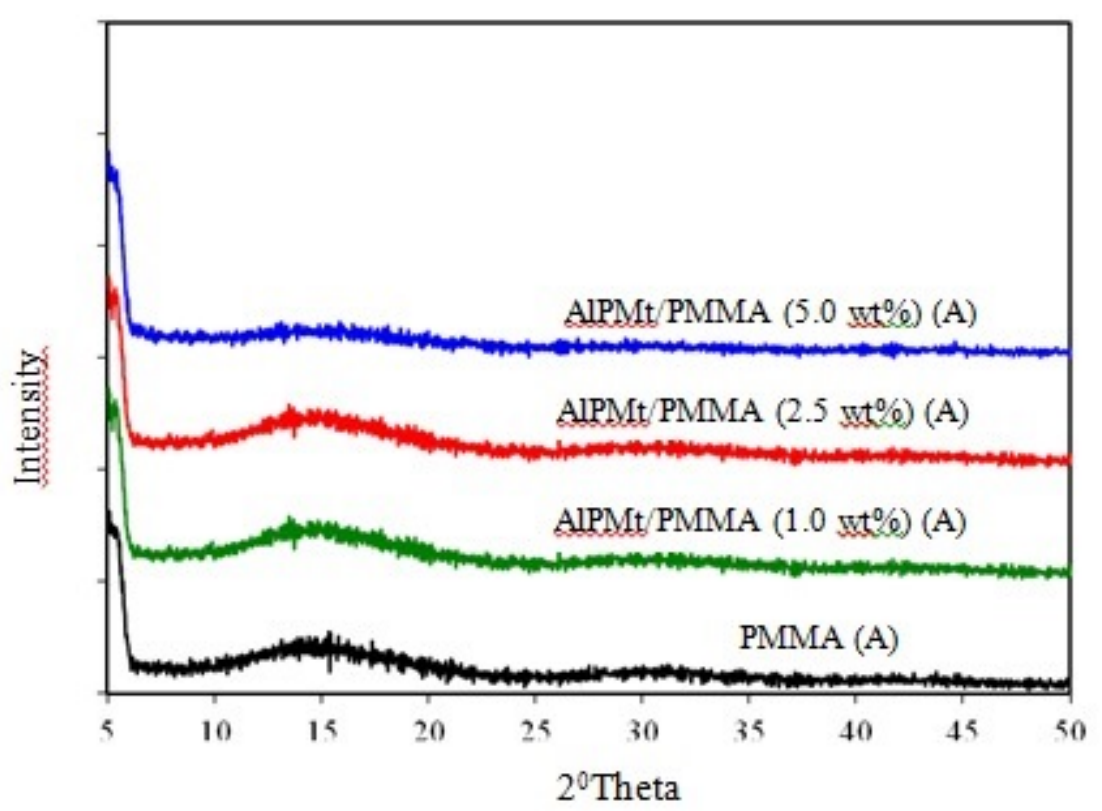

Fig. 4. XRD patterns of AIPMt/PMMA nanocomposites with SBM

Solubility parameters of polymer and solvents which were close each other showed that the solvents were suitable for this polymer. Figure 3 shows XRD patterns of AlPMt/PMMA nanocomposites $(2.5 \mathrm{wt} \%)$ preparing in different solvents. In Figure 3, any characteristic XRD reflection of AlPMt was not seen in XRD patterns of AlPMt/PMMA nanocomposites. Hence, AlPMt disperses in the polymer matrix in the form of columns [29,30], and also the different solvents for PMMA nanocomposites does not occur a significant difference in the XRD patterns. Figure 4 shows XRD pattern of AlPMt/PMMA nanocomposites. The dispersion of phyllosilicate was not affected with preparing methods and increasing of clay amount and clay dispersed in polymer matrix as homogeneously.

\section{Morphology of Nanocomposites}

The degree of dispersion of AlPMt into PMMA matrix was studied by XRD and also by TEM. Figure 5 shows the TEM images of AlPMt/PMMA $(2.5 \mathrm{wt} \%)$ nanocomposite for MBM and Figure 6 shows the TEM images of AlPMt/PMMA (2.5 wt $\%$ ) nanocomposite for SBM by using different solvents. This technique has been used in order to observe the clay platelet structure, which are distinguished by the dark zones [31]. The pillared clay layers were dispersed uniformly and homogeneously in the polymer matrix which was evidence for the intercalated morphology. The images showed the homogeneity of dispersions on nanometer scale, in accordance with XRD results. However, the pillared clay was more homogeneously dispersed in TEM images of nanocomposites synthesized by MBM and XRD data supports this conclusion.

\section{Atomic Force Microscopy (AFM) Analysis}

AFM images of AlPMt/PMMA nanocomposites have been given in Figure 7. Surface roughness of neat polymer was less than CPNs which included different amounts of filler. Surface roughness of AlPMt/PMMA (2.5 wt $\%$ ) was less than the other samples. As parallel with the results of other analyzes, this situation can be explained by the homogeneous dispersion of the filler in the polymer matrix. However, in some cases, clay layers that are around the polymer can be aggregated. The increase in the surface roughness due to the 
increase of the amount of Al-MMT pillared clay used as filler material was obviously seen in three-dimensional AFM images. However, since AFM analyzes take measurements in the nanometer range, it should also be known that the measured values do not represent severe roughness.
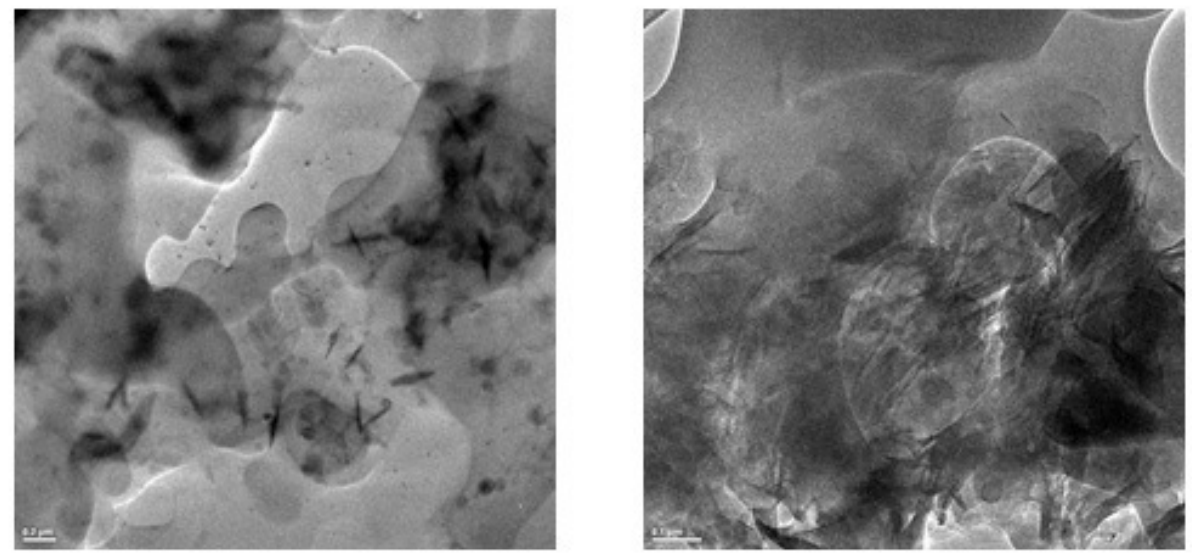

Fig. 5. TEM images of AIPMt/PMMA (2.5 wt.\%) nanocomposites synthesized via MBM

a)

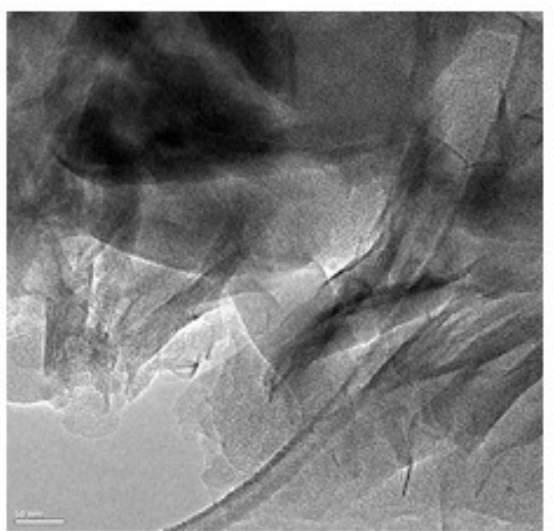

c)

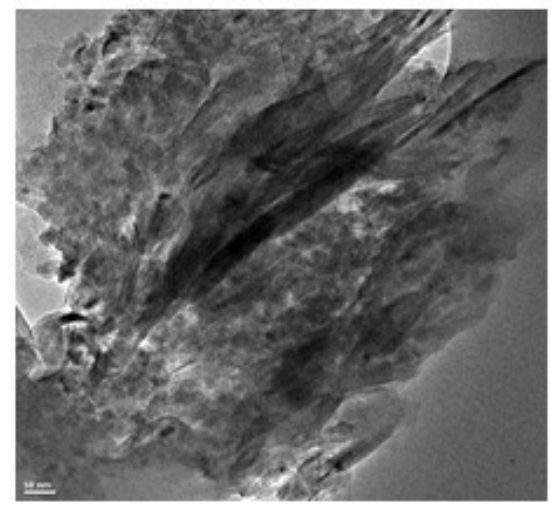

b)

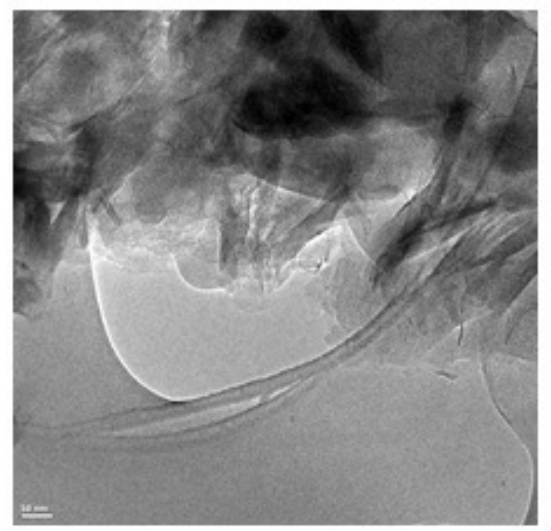

d)

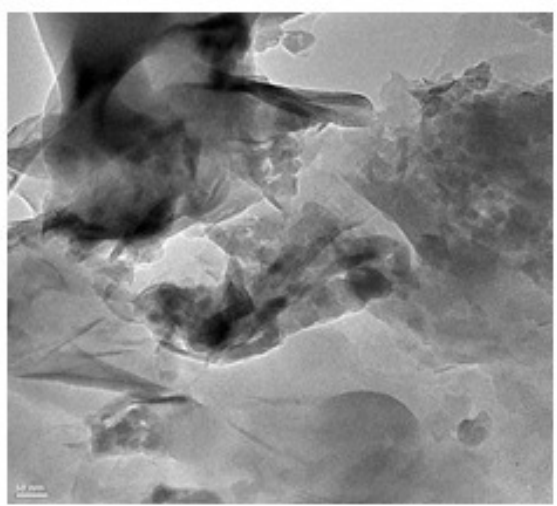

Fig. 6. TEM images of AIPMt/PMMA (2.5 wt\%) nanocomposites synthesized via SBM by using different solvents a) A, b) Ch, c) T, d) THF 
a)

b)

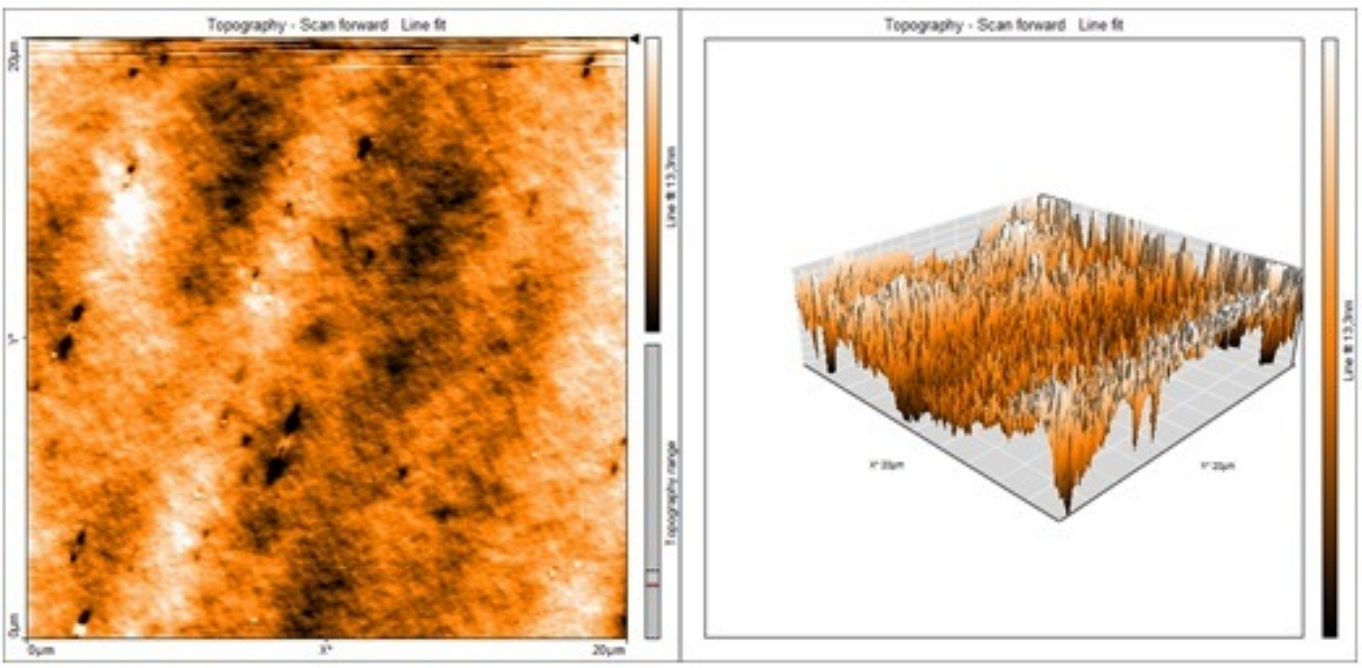

c)

d)

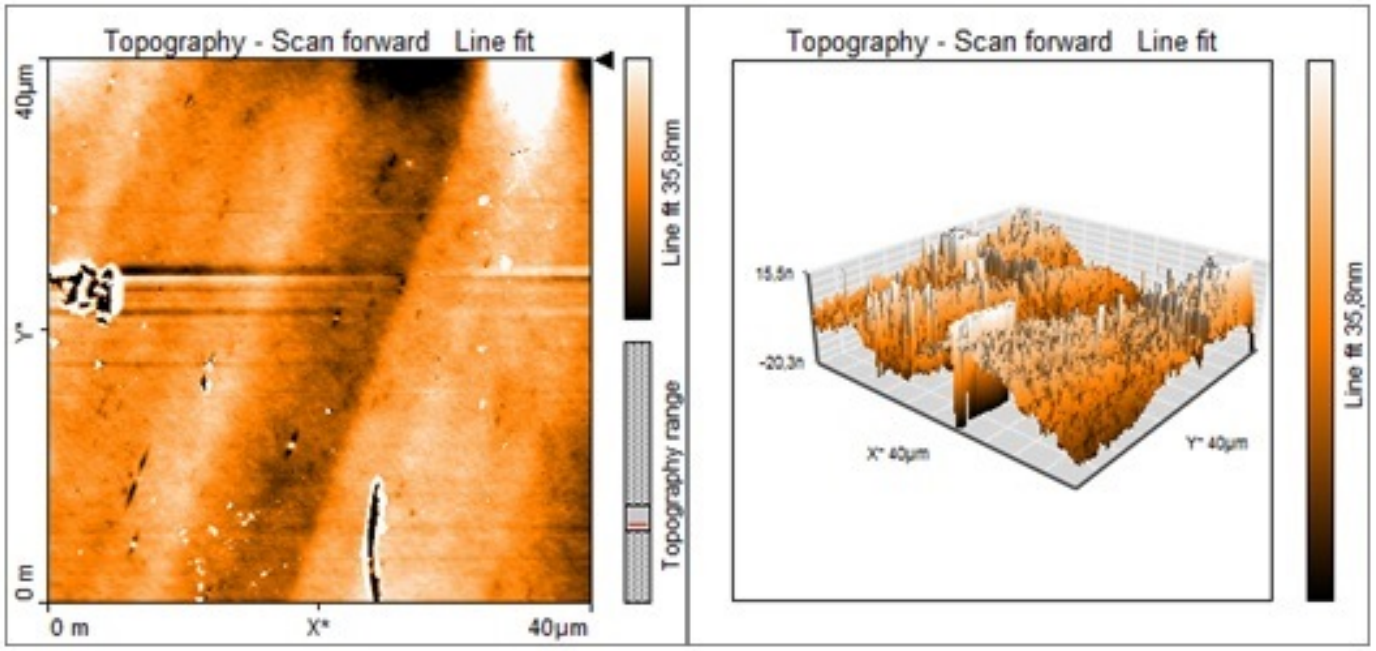

e)

f)

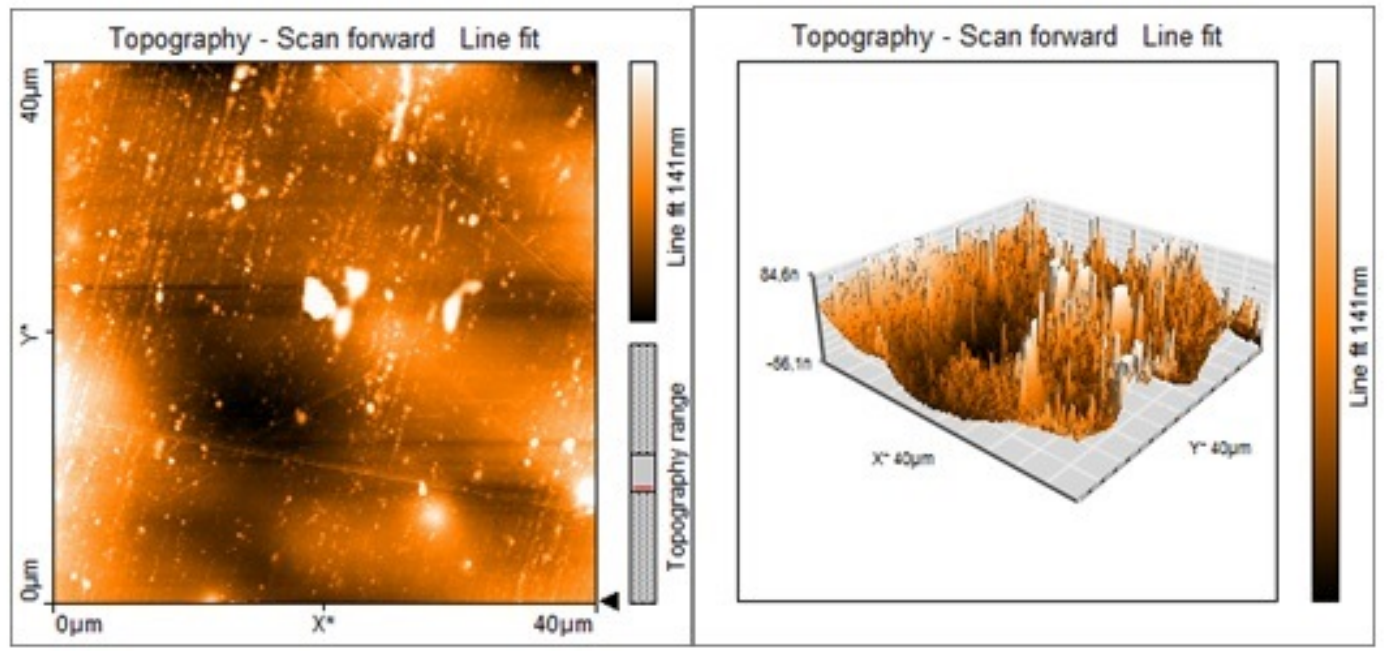


g)

h)

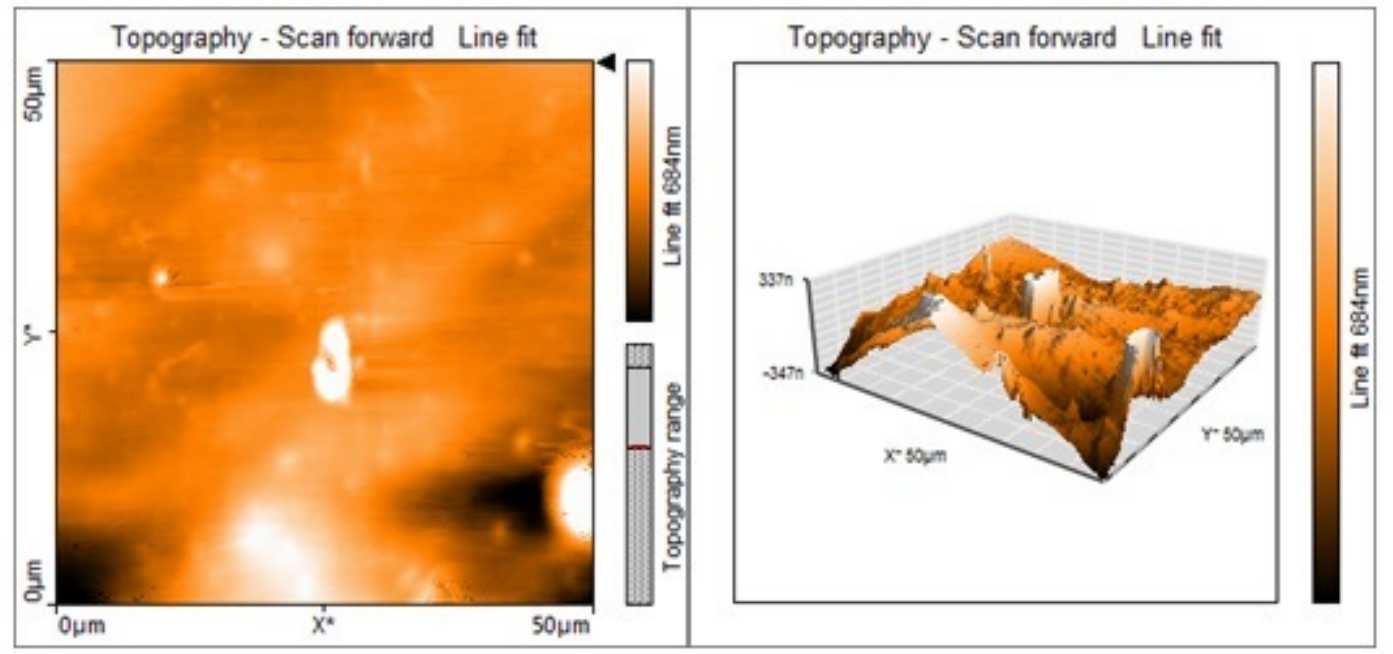

Fig. 7. AFM images of a-b) PMMA, c-d) AIPMt/PMMA (1.0 wt $\%)$, e-f) AIPMt/PMMA (2.5 wt $\%$ ) and g-h) AIPMt/PMMA (5.0 wt\%) nanocomposites

\section{FTIR Analysis of Nanocomposites}

FTIR-ATR spectra of PMMA show asymmetric stress peak of aliphatic C-H $\left(2994 \mathrm{~cm}^{-1}\right)$, symmetric stress peak of $\mathrm{C}-\mathrm{H}$ and $(\mathrm{C}) \mathrm{CH}_{3}\left(2950 \mathrm{~cm}^{-1}\right)$, peak of $>\mathrm{C}=\mathrm{O}\left(1722 \mathrm{~cm}^{-1}\right)$, bending peaks of $\mathrm{CH}_{3},-\mathrm{CH}_{2}, \mathrm{O}-\mathrm{CH}_{2-}\left(1435 \mathrm{~cm}^{-1}\right)$, a band of functional group $\mathrm{C}(\mathrm{C}=\mathrm{O})-\mathrm{O}\left(1239 \mathrm{~cm}^{-1}\right)$ and a peak of $\mathrm{C}-\mathrm{O}\left(1142 \mathrm{~cm}^{-1}\right)$. The interaction between polymer and filler during the synthesis of nanocomposites can be examined by FTIR-ATR. When the spectrum of nanocomposites interprets, peaks of these groups have been taken into consideration. FTIR spectra obtained for AlPMt/PMMA nanocomposites have been shown in Figures 8, 9 and 10. From the figures, it can be seen that $\mathrm{C}=\mathrm{O}$ and $\mathrm{C}-\mathrm{O}$ peaks for AlPMt/PMMA nanocomposites have shifted to a lower wavelength, the slip of $\mathrm{C}=\mathrm{O}$ peak has decreased with increase in the percentage of clay and the slip of $\mathrm{C}-\mathrm{O}$ peak increases. Thus, spectra show that the interaction between the AlPMt and PMMA proceeds via $\mathrm{C}=\mathrm{O}$ and $\mathrm{C}-\mathrm{O}$ groups and this is summarized in scheme 1.

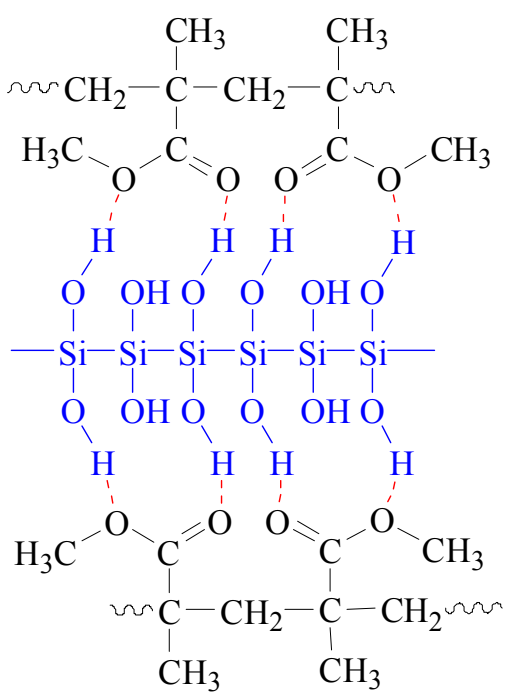


The peak of $\mathrm{C}-\mathrm{H}$ bending vibration at $1033 \mathrm{~cm}^{-1}$ which belongs to FTIR spectrum of PMMA was not observed in the case of nanocomposite. When the medium conditions of THF and A solvents were examined, $\mathrm{C}-\mathrm{O}$ peak of nanocomposites in the $\mathrm{A}$ and $\mathrm{C}=\mathrm{O}$ and $\mathrm{C}-\mathrm{O}$ peaks of nanocomposite shifted to dissimilar wavelength. Also, FTIR-ATR spectra of nanocomposites which were synthesized by adding of different amounts of AlPMt into PMMA matrix showed that there was a significant interaction between PMMA and AIPMt in the Figure 8.

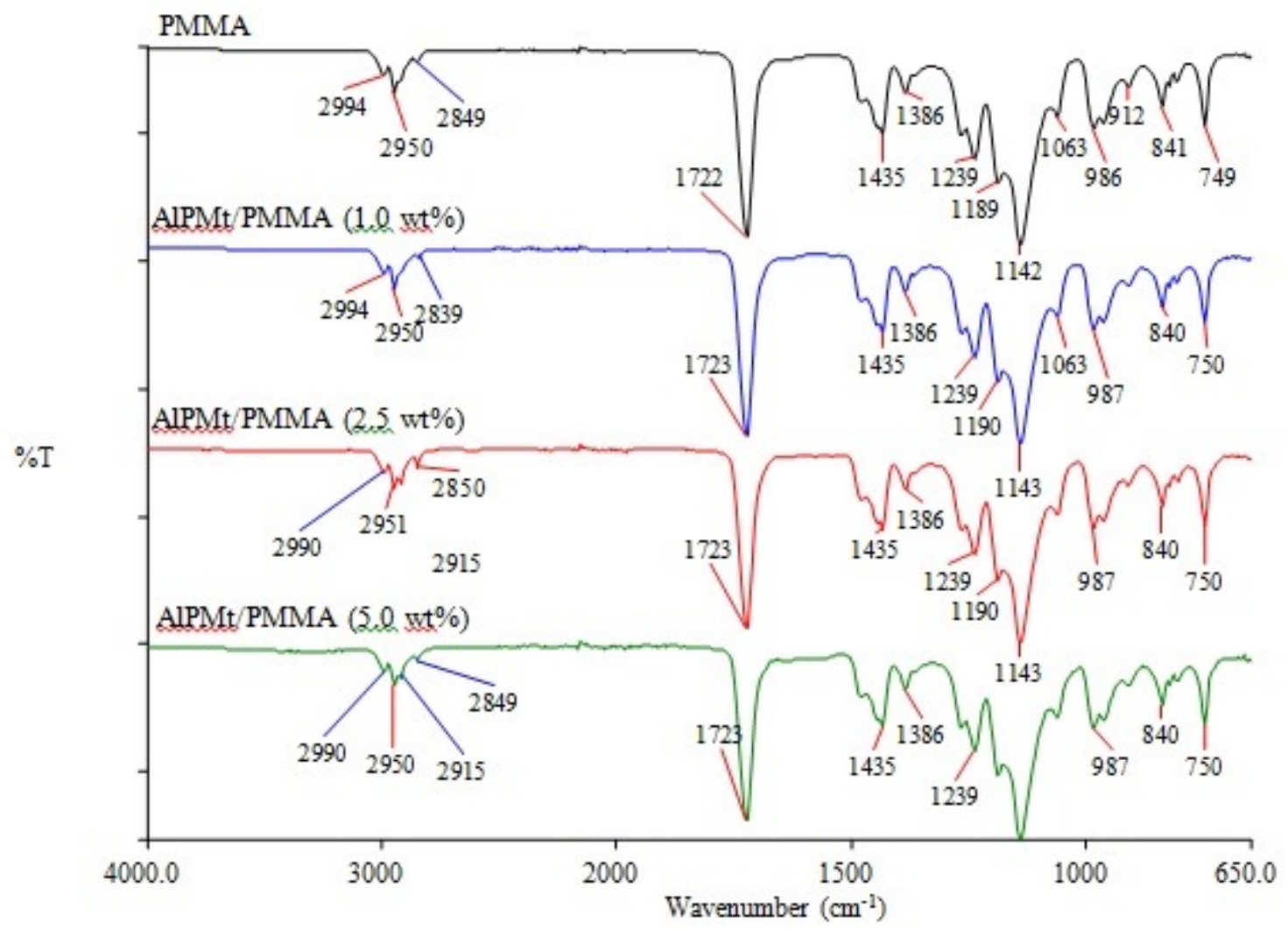

Fig. 8. FTIR-ATR spectra of AIPMt/PMMA nanocomposites with MBM

\section{DTA/TG Analysis of AlPMt}

TG measures the amount and rate of weight change of sample as it is heated at a specified rate, while DTA measures the difference in temperature between the sample and a thermally inert reference material as it is heated. Figure 11 has shown the thermogravimetric analysis and differential thermal analysis thermograms from 25 to $1200^{\circ} \mathrm{C}$ for AlPMt. The weight loss in the TG curve peaking near $86^{\circ} \mathrm{C}$ and DTA curve at $89^{\circ} \mathrm{C}$ may be ascribed to physisorbed (free) water held in interparticle pores [32], and a small S-shaped endo-exotherm peak at $968^{\circ} \mathrm{C}$ attributed to the formation of new phases such as spinel, cristobalite, and mullite. Pillared clay has shown high thermal stability and the total weight loss (residue) for AlPMt was calculated $85.7 \%$ from 25 to $1200^{\circ} \mathrm{C}[33,34]$. 


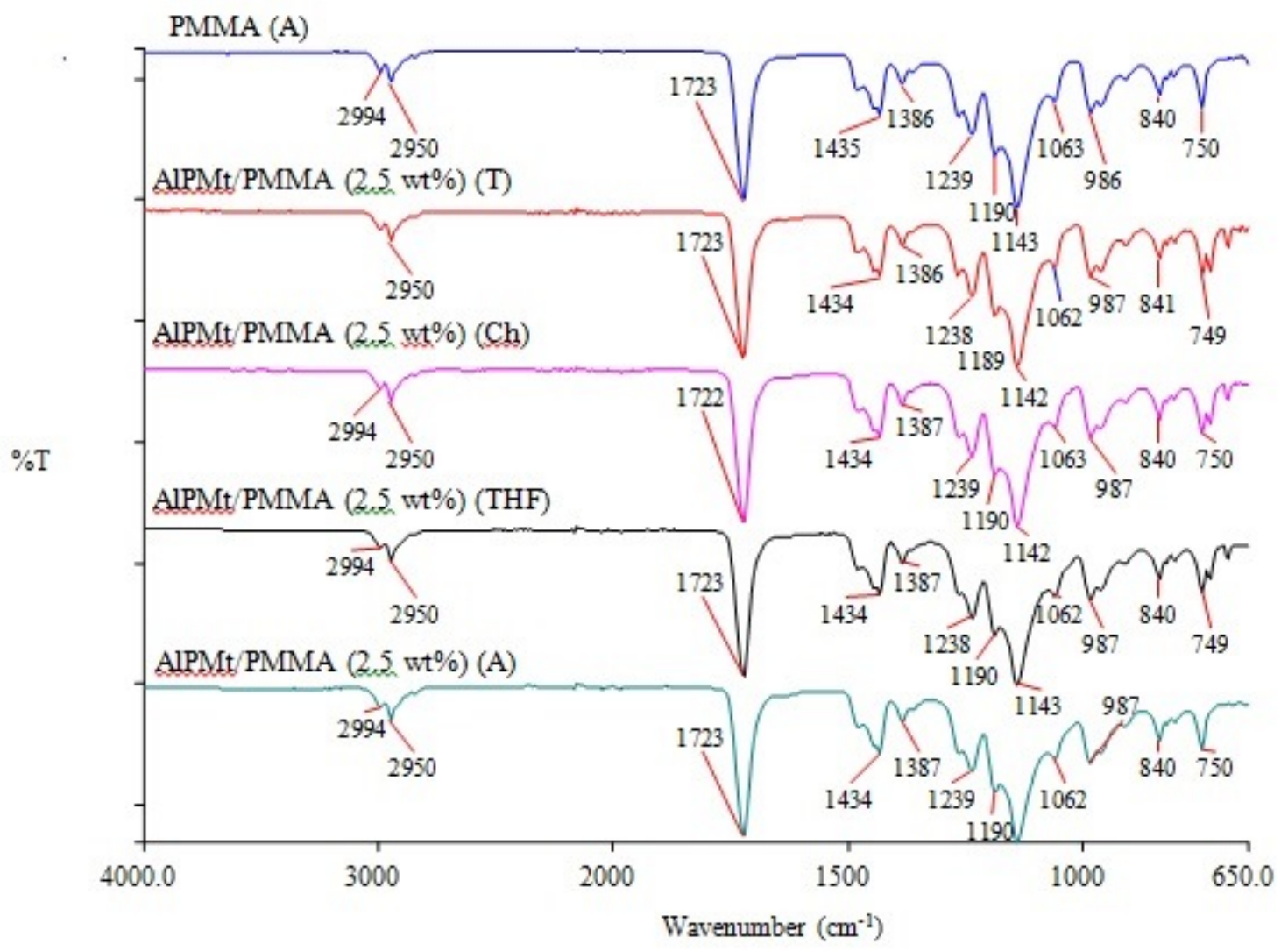

Fig. 9. FTIR-ATR spectra of AIPMt/PMMA nanocomposites with SBM by using different solvents

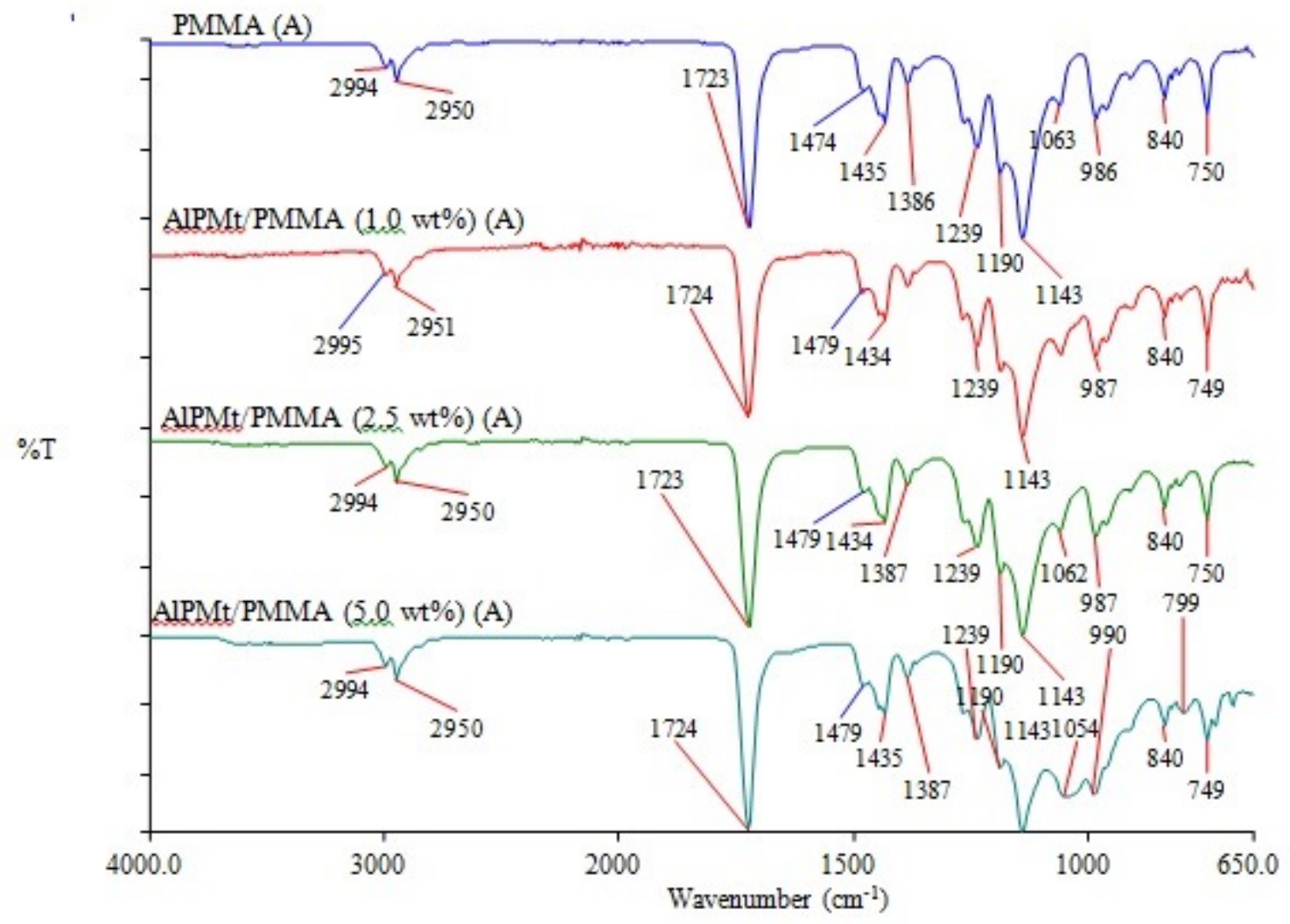

Fig. 10. FTIR-ATR spectra of AIPMt/PMMA nanocomposites with SBM 


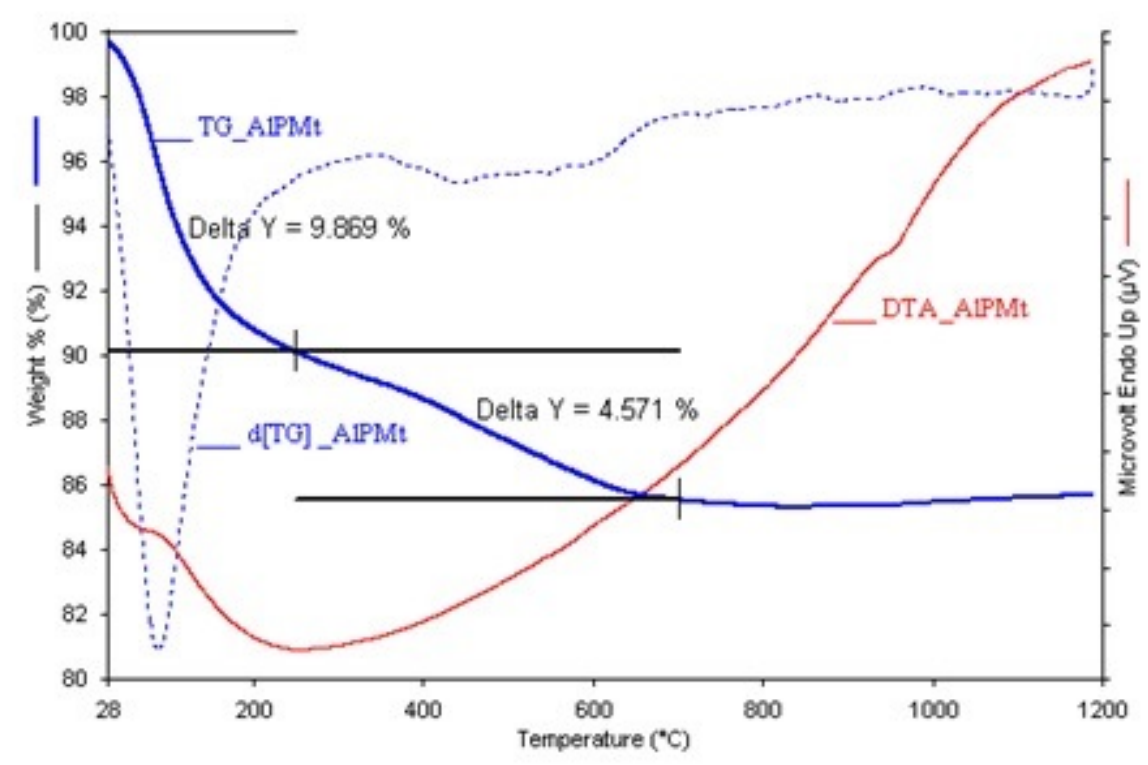

Fig. 11. TG and DTA thermograms of AIPMt

\section{TG and DSC Analysis of Nanocomposites}

The thermal degradation of PMMA has been in detail investigated during last decades. The decomposition of PMMA has three initiation processes. The first process is initiation by weak linkages between 155 and $220^{\circ} \mathrm{C}$. The second one is initiation by labile chain ends (terminal bonds and unsaturation or initiator moieties) between 230 and $300^{\circ} \mathrm{C}$. The last one is random chain scission of $\mathrm{C}-\mathrm{C}$ bonds at the repeat unit over $330{ }^{\circ} \mathrm{C}$. Afterwards, a radical is formed. This thermal degradation mechanism is shown in scheme 2 [35].

$$
\begin{aligned}
& \begin{array}{clll}
\mathrm{CH}_{3} & \mathrm{CH}_{3} & \mathrm{CH}_{3} & \mathrm{CH}_{3} \\
\mathrm{CH}_{2}-\mathrm{C}-\mathrm{CH}_{2}- & \mathrm{C}-\mathrm{CH}_{2}- & \mathrm{C}-\mathrm{CH}_{2}- & \mathrm{C} \\
\mathrm{C}=\mathrm{O} & \mathrm{C}=\mathrm{O} & \mathrm{C}=\mathrm{O} & \mathrm{C}=\mathrm{O} \\
\mathrm{l}=\mathrm{OH}_{3} & \mathrm{I} \mathrm{OCH}_{3} & \mathrm{I} \mathrm{OCH}_{3} & \mathrm{OCH}_{3}
\end{array}
\end{aligned}
$$

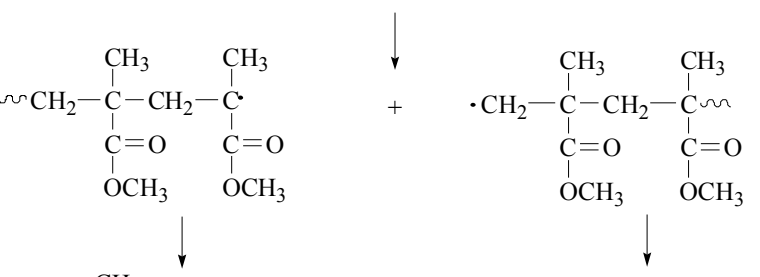

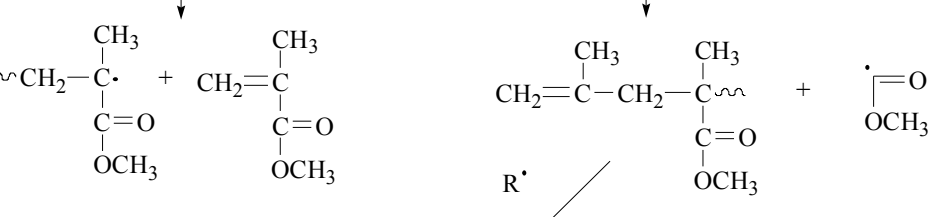

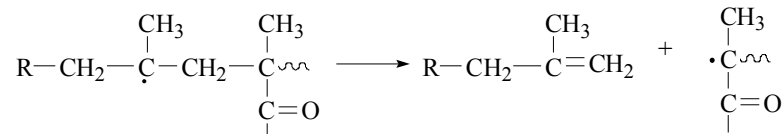

$$
\begin{aligned}
& \mathrm{OCH}_{3} \quad \mathrm{OCH}_{3}
\end{aligned}
$$


Figures 12 and 13 show the thermogravimetric analysis and differential thermal analysis thermograms from 25 to $600^{\circ} \mathrm{C}$ for nanocomposites synthesized with two different methods. Table 1 shows the temperatures $\left(\mathrm{T}_{5}, \mathrm{~T}_{10}, \mathrm{~T}_{50}\right.$ and $\left.\mathrm{T}_{80}\right)$ at $5,10,50$ and $80 \mathrm{wt} \%$ weight loss of neat PMMA and AlPMt/PMMA nanocomposites with different solvents or different AlPMt loadings under $\mathrm{N}_{2}$ atmosphere. In general, $\mathrm{T}_{5}, \mathrm{~T}_{10}, \mathrm{~T}_{50}$ and $\mathrm{T}_{80}$ values increase with increase of filler content in the case of nanocomposite. As similar to our results, many studies indicate that the nanoscale compounding of the clay particles improves the thermal stability of AlPMt/polymer nanocomposites, for instance, in cases where the polymer matrices are polystyrene [36], poly(methyl methacrylate) [37,38] and polypropylene [39]. The presence of AlPMt enhances the formation of char and hinders diffusion of volatile decomposition products within the nanocomposites [16]. In addition, the data of Table 1 show that the residue of neat PMMA is almost $0 \mathrm{wt} \%$ and the residue of nanocomposites increases with the increase of AlPMt content at $600^{\circ} \mathrm{C}$. The mass increase of residue is proportional to the AlPMt content. $\mathrm{T}_{\max }$ is the temperature corresponding to the inflection point of the thermal degradation. These values have increased with the preparation method, solvent and AlPMt content. The highest increasing belongs to the AlPMt/PMMA $(2.5 \mathrm{wt} \%)$ sample prepared by MBM. This situation shows that AlPMt effectively retards the early stage of PMMA degradation. Compared to the solvent mediums shown in Table 1, the thermal stability values of the AlPMt/PMMA nanocomposites were usually found to be the best that in A. The higher thermal stability values in PMMA nanocomposites synthesized with A suggests that AlPMt makes the random chain fragmentation of $\mathrm{C}-\mathrm{C}$ bonds in the repeating unit more or less difficult in the structure of PMMA.

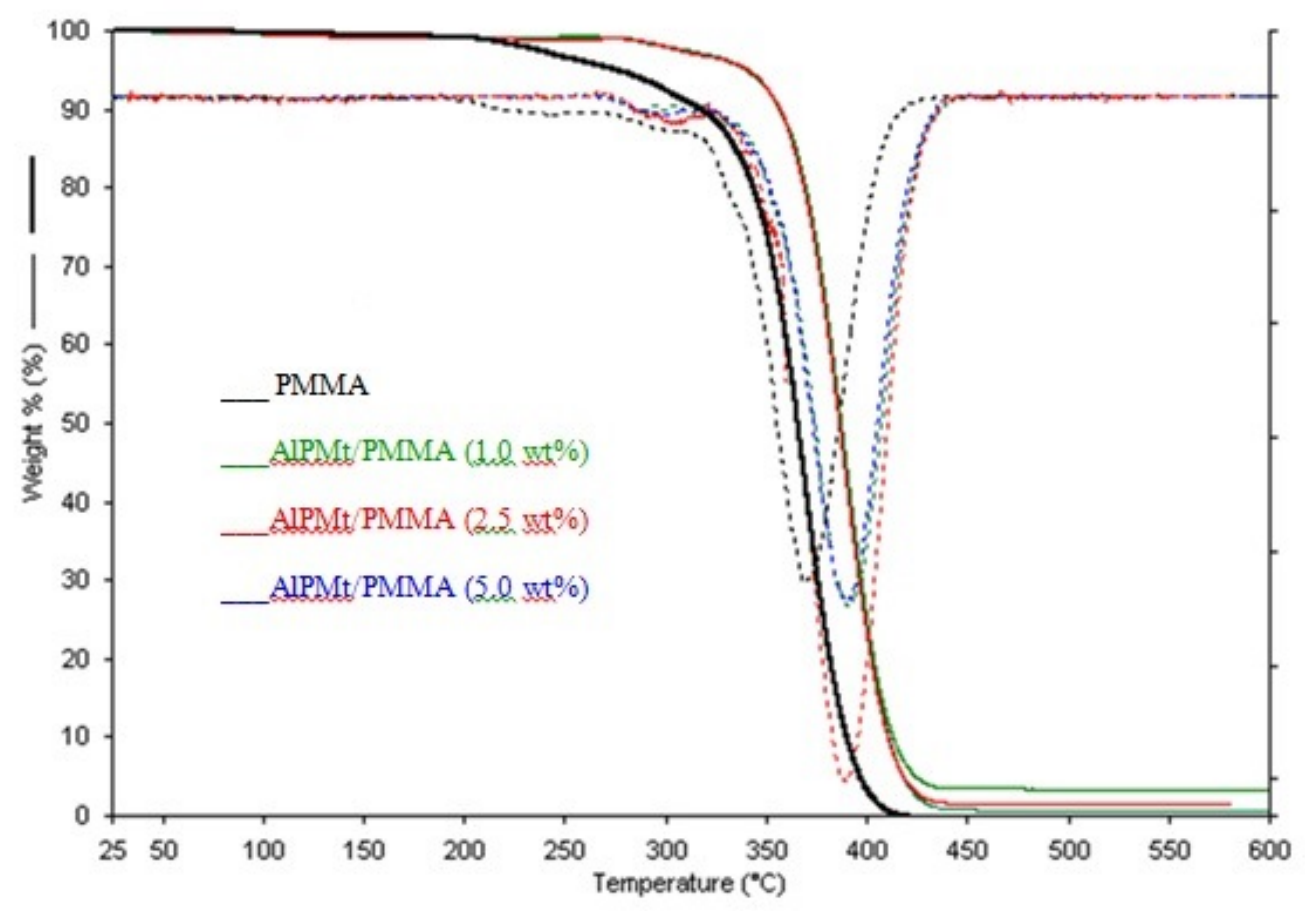

Fig. 12. $T G / d[T G]$ thermograms of neat PMMA and AIPMt/PMMA nanocomposites with MBM 
a)

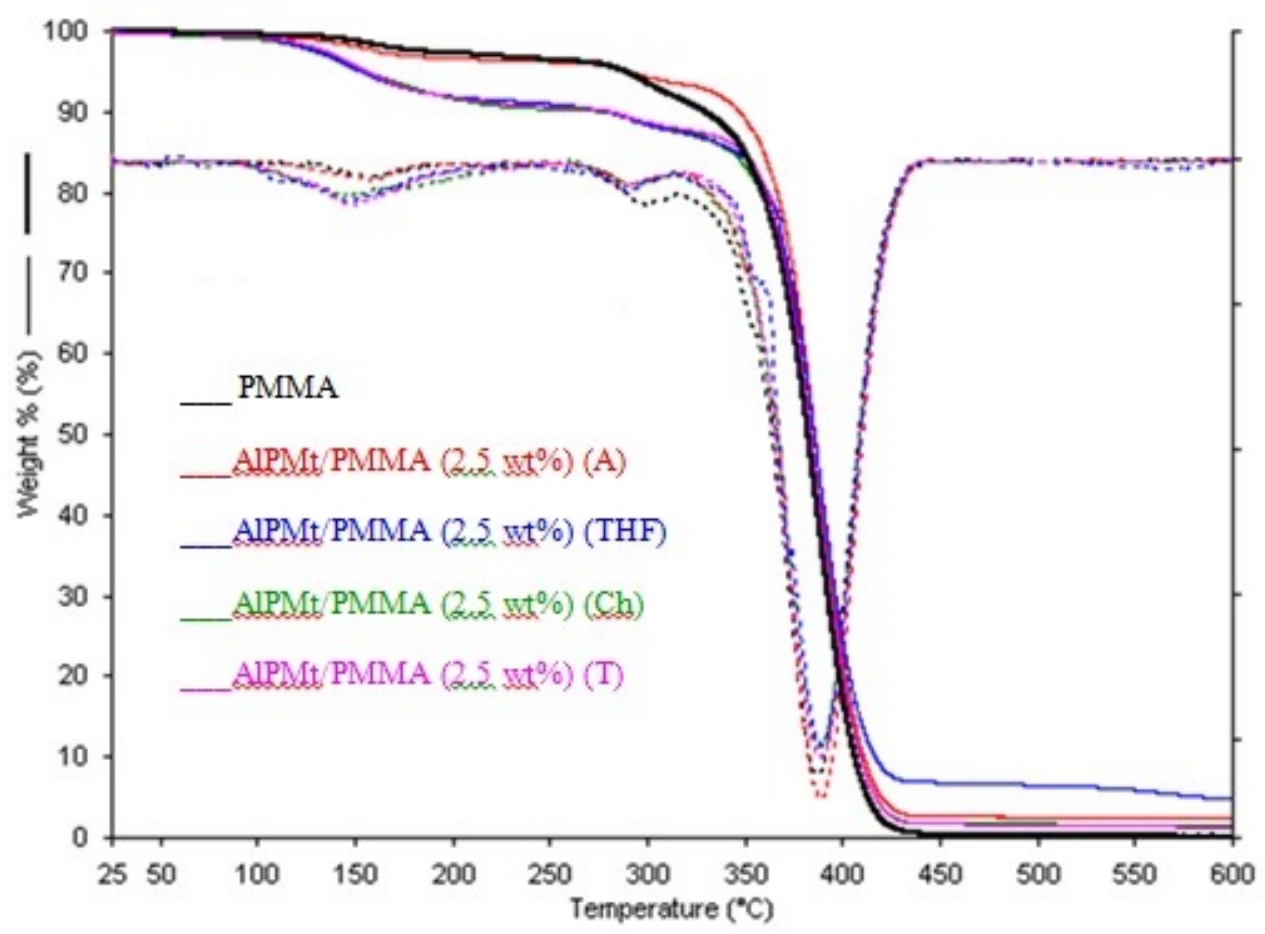

b)

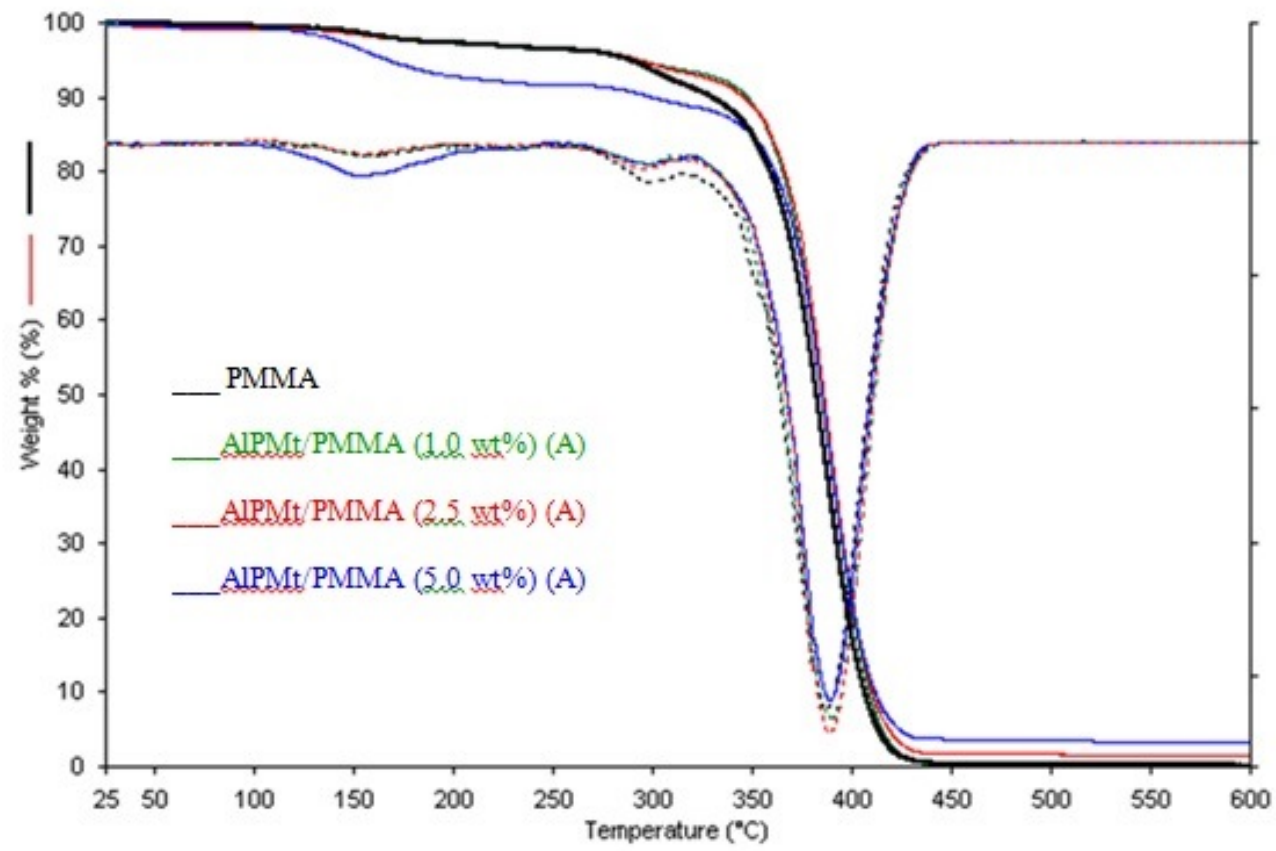

Fig. 13. TG/d[TG] thermograms of neat PMMA and AIPMt/PMMA nanocomposites with SBM using a) different solvents, b) $A$

The values given in Table 1 indicate that the thermal properties of pure PMMA are increased by adding AlPMt into the PMMA matrix. $\mathrm{T}_{\mathrm{g}}$ temperatures for nanocomposites are 
generally higher than neat PMMA [40]. $\mathrm{T}_{g}$ values of nanocomposites synthesized by SBM using $\mathrm{A}$ as a solvent are higher than neat PMMA but this value decreases with increasing clay content. In particular, AlPMt/PMMA (2.5 wt \%) (A) and AlPMt/PMMA (5.0 wt \%) (A) have shown a huge difference in $\mathrm{T}_{\mathrm{g}}$ values. The reason of this difference may be the barrier effect of the clay by increasing clay concentration. This situation can be explained by the more difficult distribution of clay in the polymer matrix when the amount of clay is increased. $\mathrm{T}_{\mathrm{g}}$ temperature values of the nanocomposites synthesized by the SBM using other solvents were lower than that of neat PMMA. $\mathrm{T}_{\mathrm{g}}$ temperature of the nanocomposites obtained by the MBM were increased about $11-12^{\circ} \mathrm{C}$ by adding clay. In Table $1, \mathrm{~T}_{\mathrm{g}}$ values of nanocomposites synthesized by SBM were lower when compared with the nanocomposites synthesized by MBM. This difference can be explained by the fact that the solvents are not removed completely. By increasing clay concentration, the removal of solvent is more hindered due to the barrier effect of the clay. When the $\mathrm{T}_{\mathrm{g}}$ temperatures of the nanocomposites were compared with each other, the AlPMt/PMMA nanocomposite containing $2.5 \mathrm{wt} \%$ filler material had the highest thermal stability.

Table 1. Thermal stability parameters of PMMA and AIPMt/PMMA nanocomposites

\begin{tabular}{|l|c|c|c|c|c|c|c|}
\hline Samples & $\begin{array}{c}\mathrm{T}_{5} \\
{ }^{\circ} \mathrm{C}\end{array}$ & $\begin{array}{c}\mathrm{T}_{10} \\
{ }^{\circ} \mathrm{C}\end{array}$ & $\begin{array}{c}\mathrm{T}_{50} \\
{ }^{\circ} \mathrm{C}\end{array}$ & $\begin{array}{c}\mathrm{T}_{80} \\
{ }^{\circ} \mathrm{C}\end{array}$ & $\begin{array}{c}\mathrm{T}_{\max } \\
{ }^{\circ} \mathrm{C}\end{array}$ & $\begin{array}{c}\text { Residue } \\
\%\end{array}$ & $\begin{array}{c}\mathrm{T}_{\mathrm{g}} \\
{ }^{\circ} \mathrm{C}\end{array}$ \\
\hline PMMA (A) & 288 & 329 & 382 & 398 & 385 & 0.157 & 101 \\
\hline PMMA (THF) & 152 & 270 & 380 & 396 & 385 & 0.144 & 80 \\
\hline PMMA (Ch) & 154 & 272 & 380 & 397 & 384 & 0.136 & 81 \\
\hline PMMA (T) & 154 & 280 & 375 & 396 & 384 & 0.124 & 80 \\
\hline AlPMt/PMMA (1.0 wt\%) (A) & 293 & 347 & 385 & 401 & 390 & 0.252 & 107 \\
\hline AlPMt/PMMA (2.5 wt\%) (A) & 207 & 341 & 386 & 403 & 390 & 3.346 & 102 \\
\hline AlPMt/PMMA (5.0 wt\%) (A) & 167 & 299 & 385 & 401 & 390 & 3.311 & 84 \\
\hline $\begin{array}{l}\text { AlPMt/PMMA (2.5 wt\%) } \\
\text { (THF) }\end{array}$ & 151 & 276 & 285 & 401 & 390 & 2.489 & 81 \\
\hline AlPMt/PMMA (2.5 wt\%) (Ch) & 155 & 276 & 383 & 400 & 388 & 1.471 & 83 \\
\hline AlPMt/PMMA (2.5 wt\%) (T) & 156 & 281 & 384 & 400 & 387 & 1.314 & 82 \\
\hline PMMA & 275 & 317 & 366 & 382 & 366 & 0 & 104 \\
\hline AlPMt/PMMA (1.0 wt\%) & 341 & 356 & 387 & 403 & 388 & 0.609 & 115 \\
\hline AlPMt/PMMA (2.5 wt\%) & 345 & 358 & 388 & 403 & 393 & 2.066 & 116 \\
\hline AlPMt/PMMA (5.0 wt\%) & 340 & 356 & 387 & 403 & 388 & 3.736 & 115 \\
\hline
\end{tabular}

\section{Contact Angle Measurements}

Figure 14 shows the contact angles of PMMA and its nanocomposites measured with $\mathrm{H}_{2} \mathrm{O}$ as the solvent. PMMA is basically a hydrophobic polymer and contact angle of neat polymer was measured as $84.50^{\circ}$, which may be ascribed to the altered surface roughness. The surface roughness and the porosity have significant effect on the apparent contact angle [41]. PMMA nanocomposite films with enhanced surface roughness and porosity results in lower contact angle when compared with the literature [42]. The contact angle decreased with the addition of AlPMt into the polymer matrix since AlPMt which was a layered silicate had higher hydrophilic character than PMMA. Consequently, AlPMt/PMMA (5.0 wt \%) nanocomposite shows lower contact angle or higher hydrophilicity than the other nanocomposites with the less content of AlPMt. 
a)

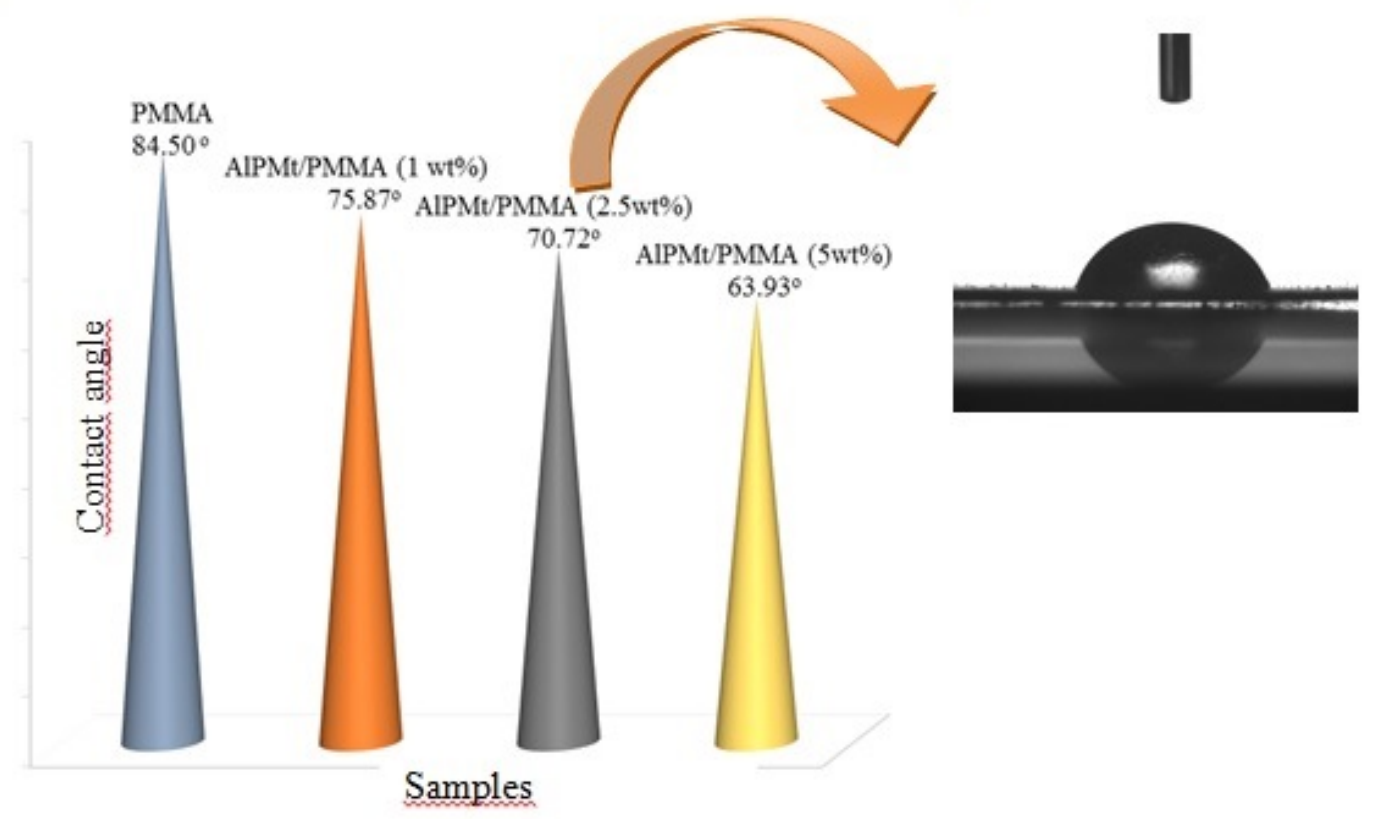

Fig. 14. a) Contact angle of PMMA and AIPMt/PMMA nanocomposites, b) image of AIPMt/PMMA (2.5 wt\%) sample

\section{CONCLUSION}

AlPMt was introduced into PMMA polymer matrix to prepare the CPNs by solvent blending and melt blending methods. The characterization of CPNs was made by FTIR-ATR, XRD and TEM. The presence of the infrared bands in AlPMt/PMMA nanocomposite indicated that AlPMt was interfered with PMMA and the hydrogen bond interactions between them were occurred. The results of XRD showed that AlPMt was homogeneously dispersed in the PMMA matrix. TEM results were correlated with the XRD patterns. The thermal properties of the synthesized AlPMt/PMMA nanocomposites were also investigated. AlPMt/PMMA nanocomposite synthesized via MBM showed the higher decomposition temperature and glass transition temperature in comparison with neat PMMA. The nanocomposites enhanced the formation of residue and improved the thermal stability of the polymer matrix. AlPMt/PMMA nanocomposite powder was perfectly dispersed in acetone, partly dispersed in chloroform and THF. Furthermore, it was found that there were more improvements in the thermal properties of polymer by melt blending method. The results showed that the AlPMt could be used in the production of polymer-based nanocomposites.

\section{REFERENCES}

1. Olad A., Polymer/Clay Nanocomposites. Advances in Diverse Industrial Applications of Nanocomposites. 2011, 114.

2. Ge Z., Li D., Pinnavaia T.J., Preparation of alumina-pillared montmorillonites with high thermal stability, regular microporosity and Lewis/Brönsted acidity. Microporous Mater. 1994, 3, 165. 
3. Tsai T.Y., Lin M. J., Chang C. W., Li C.C., Morphology and properties of poly(methyl methacrylate)/clay nanocomposites by in-situ solution polymerization. J. Phys. Chem. Solids. 2010, 71, 590 .

4. Valandro S.R., Lombardo P.C., Poli A.L., Horn M.A., Neumann M.G., Cavalheiro C.C., Thermal properties of poly (methyl methacrylate)/organomodified montmorillonite nanocomposites obtained by in situ photopolymerization. Mater. Res. 2014, 17, 265.

5. Zhang J., Gupta R.K., Wilkie C.A., Controlled silylation of montmorillonite and its polyethylene nanocomposites. Polymer. 2006, 47, 4537.

6. Nguyen QT., Baird D.G., Preparation of polymer-clay nanocomposites and their properties. Adv. Polym. Tech. 2006, 25, 270.

7. $\quad \mathrm{Xu} \mathrm{H.,} \mathrm{Tong} \mathrm{F.,} \mathrm{Yu} \mathrm{J.,} \mathrm{Wen} \mathrm{L.,} \mathrm{Zhang} \mathrm{J.,} \mathrm{He} \mathrm{J.,} \mathrm{A} \mathrm{one-pot} \mathrm{method} \mathrm{to} \mathrm{prepare} \mathrm{transparent}$ poly(methyl methacrylate)/montmorillonite nanocomposites using imidazolium-based ionic liquids. Polymer International. 2012, 61, 1382.

8. Choudhury A., Bhowmick, A.K., Ong C., Novel role of polymer-solvent and clay-solvent interaction parameters on the thermal, mechanical and optical properties of polymer nanocomposites. Polymer. 2009, 50, 201.

9. Messersmith P.B., Giannelis E.P., Polymer layered silicate nanocomposites: in situ intercalative polymerization of $\varepsilon$-caprolactone in layered silicates. Chem. Mater. 1993, 5, 1064.

10. Yano K., Usuki, A., Okada, A., Kurauchi T., Kamigaito O., Synthesis and properties of polyimide-clay hybrid. J. Polym. Sci., Part A: Polym. Chem. 1993, 31, 2493.

11. Giannelis E.P., Polymer layered silicate nanocomposites. Adv. Mater. 1996, 8, 29.

12. Gianni A.D., Amerio E., Monticelli O., Bongiovanni, R., Preparation of polymer/clay mineral nanocomposites via dispersion of silylated montmorillonite in a UV curable epoxy matrix. Appl. Clay Sci. 2008, 42, 116.

13. Alberti G., Constantino U., Layered solids and their intercalation chemistry. In Comprehensive Supramolecular Chemistry. 1996, 7, 1.

14. Schoonheydt R.A., Pinnavaia T., Lagaly G., Gangas N., Pillared clays and pillared layered solids. Pure Appl. Chem. 1999, 71, 2367.

15. Bhattacharyya K.G., Gupta S., Adsorption of a few heavy metals on natural and modified kaolinite and montmorillonite: A review. Adv. Colloid Interface Sci. 2008, 140, 114.

16. Burch R., Pillared Clays. Special Edition of Catal. Today; Elsevier: Amsterdam, 1988.

17. Gong F., Feng M., Zhao C., Zhang S., Yang M., Thermal properties of poly(vinyl chloride)/montmorillonite Nanocomposites. Polym. Degrad. Stab. 2004, 84, 289.

18. Modak S.K., Mandal A., Chakrabarty D., Studies on synthesis and characterization of poly(methyl methacrylate)-bentonite clay composite by emulsion polymerization and simultaneous in situ clay incorporation. Polym. Compos. 2013, 34, 32.

19. Huskic M., Zagar E., Zigon M., The influence of a quaternary ammonium salt and MMT on the in situ intercalative polymerization of PMMA. Eur. Polym. J. 2012, 48, 1555-1590.

20. Huskic M., Zigon M., PMMA/MMT nanocomposites prepared by one-step in situ intercalative solution polymerization. Eur. Polym. J. 2007, 43, 4891.

21. Turhan Y., Alp Z.G., Alkan M., Doğan M., Preparation and characterization of poly(vinylalcohol)/modified bentonite nanocomposites. Microporous Mesoporous Mater. 2013, $174,144$.

22. Choi Y.Y., Lee S., Ryu S., Effect of silane functionalization of montmorillonite on epoxy/montmorillonite nanocomposite. Polym. Bull. 2009, 63, 47. 
23. Sposito G., Prost R., Gaultier J.P., Infrared spectroscopic study of adsorbed water on reducedcharge Na/Li-montmorillonites. Clays Clay Miner. 1983, 31, 9.

24. Ma J., Xu J., Ren J. H., Yu Z., Mai Y., A new approach to polymer/montmorillonite nanocomposites. Polymer. 2003, 44, 4619.

25. Lindvig T., Michelsen, M.L., Kontogeorgis G.M., A Flory-Huggins model based on the Hansen solubility parameters. Fluid Phase Equilibr. 2002, 203, 247.

26. Burke J., Solubility Parameters: Theory and Application. Appeared in the AIC Book and Paper Group Annual; Ed C. Jensen, 1984.

27. Richards R.W., Dilute solution properties of poly(benzyl methacrylate. Polymer. 1977, 18, 114.

28. Kaya I., Ozdemir E., Thermodynamic interactions and characterisation of poly(isobornyl methacrylate) by inverse gas chromatography at various temperatures. Polymer. 1999, 40, 2405.

29. Bergaya F., Theng B.K., Lagaly G., Handbook of Clay Science; Elsevier Science: Amsterdam, 2006, 1-1246.

30. Cool P., Vansant E.F., Preperation, charecterization and applications of pillared clays. Mol. Sieves, 1998, 1, 14.

31. Toumi I., Benyoucef A., Yahiaoui A., Quijada C., Morallon E., Effect of the intercalated cation-exchanged on the properties of nanocomposites prepared by 2-aminobenzene sulfonic acid with aniline and montmorillonite. J. Alloys Compd. 2013, 551, 212.

32. Hedley C.B., Yuan G., Theng B.K., Thermal analysis of montmorillonites modified with quaternary phosphonium and ammonium surfactants. Appl. Clay Sci. 2007, 35, 180.

33. Bergaya F., Theng B.K., Lagaly G., Pillared clays and clay minerals. Handbook of Clay Science- Developments in Clay Science; Elsevier Science: Amsterdam, 2006.

34. Jalil M.E., Baschini M., Rodríguez-Castellónc E., Infantes-Molina A., Sapag K., Effect of the $\mathrm{Al} /$ clay ratio on the thiabendazol removal by aluminum pillared clays. Appl. Clay Sci. 2014, 87, 245.

35. Pielichowski K., Njuguna J., Thermal degradation of polymeric materials. Rapra Technology Limited Shawbury; United Kingdom, 2005.

36. Chen G.M., Liu S.H., Chen S.J., Qi Z., FTIR spectra, thermal properties and dispersibility of a polystyrene/montmorillonite nanocomposite. Macromol. Chem Phys. 2001, 202, 1189.

37. Zhu J., Start P., Mauritz K.A., Wilkie C.A., Thermal stability and flame retardancy of poly(methyl methacrylate)-clay nanocomposites. Polym. Degrad. Stab. 2002, 77, 253.

38. Nikolaidis A.K., Achilias D.S., Karayannidis G.P., Effect of the type of organic modifier on the polymerization kinetics and the properties of poly(methyl methacrylate)/organomodified montmorillonite nanocomposites. Eur. Polym. J. 2012, 48, 240.

39. Zanetti M., Camino G., Peichert P., Mulhaupt R., Thermal behaviour of poly(propylene) layered silicate nanocomposites. Macromol. Rapid Commun. 2001, 22, 176.

40. Achilias D.S., Siafaka P., Nikolaidis A.K., Polymerization kinetics and thermal properties of poly(alkyl methacrylate)/organomodified montmorillonite nanocomposites. Polym. Int. 2012, 61,1510 .

41. Koysuren O., Karaman M., Yıldız H.B., Koysuren H.N., Dinc H., Electrospun polyvinyl borate/poly(methyl methacrylate) (PVB/PMMA) blend nanofibers. Int. J. Polym. Mater. 2014, $63,337$.

42. Wu P.P., Zhao D.M., Li L.X., Wang H.S., Liu G.D., Preparation of blends of poly(methyl methacrylate) copolymers with high glass transition temperatures and low hydrophilicity. Polymer Engineering and Science. 2013, 2370. 